\title{
PROCESOS, SIGNIFICADOS Y EFECTOS EN TORNO A LA CATALOGACIÓN OFICIAL DE LAS DISCAPACIDADES EN LAS MUJERES
}

\author{
Vanessa Gómez Bernal ${ }^{1}$ \\ Universidad de Cádiz
}

http://dx.doi.org/10.5209/rev_NOMA.2012.v35.n3.42204

\begin{abstract}
Resumen.- En este artículo se analiza el proceso, los significados y los efectos que conlleva la catalogación oficial en el marco de la discapacidad en las mujeres. Las personas con discapacidad se inscriben en un campo de referencia regulado por la lógica de la institucionalización: para el pleno reconocimiento de su condición de "persona con discapacidad", reconocimiento necesario para el acceso a ciertos recursos sociales, se necesita un diagnóstico que evalúe su condición y grado de discapacidad. Una vez diagnosticado su grado de discapacidad se le abrirá diversos procedimientos considerados adecuados para su inclusión social. En el caso de las mujeres, se entiende que en la catalogación oficial como "discapacitadas" influye de manera importante la conceptualización del género, como dispositivo que genera relaciones de poder.
\end{abstract}

Palabras clave.- catalogación, discapacidad, género, institucionalización

\section{Processes, meanings and effects around the official cataloging of disabilities in women}

Abstract.- This article analyzes the process, the meanings and effects involved in oficial cataloging as part of disability in women. People with disabilities are part of a reference field governed by the logic of institutionalization: the full recognition of their status as "persons with disabilities", recognizing the need for acces to certain social resources is needed to asses their condition diagnosed and degree of disability. Once diagnosed their degree of disability shall be opened various procedures considered suitable for inclusion. For women, it is understood that in the official cataloging as "disabled" significantly influences the conceptualization of gender as a device that generates power relations.

Keywords.- cataloging, disability, gender, institutionalization

\footnotetext{
${ }^{1}$ Diplomada en Trabajo Social y Licenciada en Antropología Social y Cultural por la Universidad de Granada. Título oficial de Master en Género, Identidad y Ciudadanía por la Universidad de Cádiz. Primer Premio de Investigación en Políticas de Igualdad "Carmen de Michelena" 2012 otorgado por la Diputación Provincial de Jaen. Su línea de investigación se centra sobre discapacidad y género. E-mail:v_g.bernal@hotmail.com
} 


\section{INTRODUCCIÓN²}

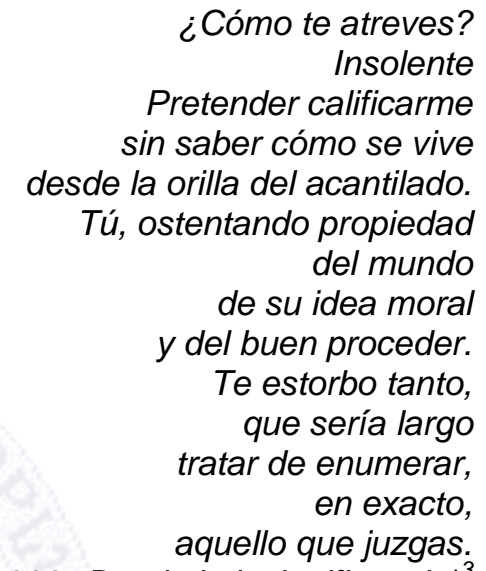

(Patricia Karina Vergara Sánchez, 2009, Desde la insignificancia) ${ }^{3}$

En este artículo se analiza el procedimiento y la conceptualización de la catalogación oficial en el marco de la discapacidad en el Estado español. Se pretende problematizar el propio proceso por el que se evalúa, valora y cataloga a las personas en un cierto grado de discapacidad, y por lo que socialmente son reconocidas, de manera oficial, como personas discapacitadas. Cuestionando los propios sistemas de clasificación que operan en el campo de la discapacidad, donde intervienen las regulaciones jurídicas, las políticas públicas, los discursos científicos, etc. En este sentido, nos enmarcamos en la perspectiva de conceptualizar la discapacidad como una determinada producción social, que se entiende que está atravesada de manera ineludible por el dispositivo de género y las desigualdades sociales que ello implica.

Por tanto, el articulo que se presenta se va a centrar, en primer lugar, en analizar el papel que cumple el Estado y la Administración pública como productores de significados y sentido en el campo de la discapacidad, lo cual significa identificar el sistema de clasificaciones y las regulaciones que se establecen para marcar los límites de pertenencia del colectivo de los discapacitados. En segundo lugar, se centra el análisis en su dimensión de género, intentado dilucidar la influencia que tiene en la catalogación de las mujeres como discapacitadas y en la propia concepción de lo que implica ser mujer con discapacidad en el contexto social actual. Por último, se presenta una parte empírica para comprender los significados y los efectos del proceso

\footnotetext{
${ }^{2}$ Agradezco los comentarios y aportaciones de la profesora Rosa Vázquez Recio y del profesor Francisco Vázquez García.

${ }^{3}$ http://www.mujeresnet.info/seccion/poesiafeminista.html Consultado el 5 de febrero de 2013.
} 
de etiquetaje de la discapacidad en diferentes ámbitos de la vida de un grupo de mujeres.

En cuanto a los aspectos metodológicos se refiere, hay que indicar que los hallazgos que se presentan son fruto de una investigación ${ }^{4}$ realizada durante el año 2012 donde se ha utilizado una metodología cualitativa e interpretativa. Asimismo, los relatos que se muestran son el resultado de la realización de entrevistas semiestructuradas, técnica que se ha utilizado a nivel grupal e individual; lo cual ha permitido explorar la perspectiva de las mujeres implicadas. Se ha entrevistado a 26 mujeres de la provincia de Cádiz y de Granada, ubicadas en el contexto del movimiento asociativo de personas con discapacidad de Andalucía. Para entrevistar a estas mujeres se ha tenido contacto en un primer momento con Asociaciones del ámbito de la discapacidad como son: Asociación Agadi (Asociación Gaditana de personas con discapacidad física), Fegadi (Federación Gaditana de Persona con discapacidad física y orgánica), Asociación Luna para la promoción de la Mujer con Discapacidad de La Línea de la Concepción y la Asociación Luna para la promoción de la Mujer con Discapacidad de Granada.

Por último, se presentan fragmentos literales de las entrevistas realizadas, donde se ha respetado la literalidad en la forma del habla oral, entendiendo por ello que no perjudica el entendimiento del contenido de lo que se dice.

\section{EL ESTADO Y LA ADMINISTRACIÓN COMO PPRODUCTORES DE SIGNIFICADOS Y SENTIDO EN TORNO A LA DISCAPACIDAD}

Los problemas de políticas públicas [en tanto] construcciones sociales que reflejan concepciones específicas de la realidad, han legitimado una visión homogeneizante y discriminadora de la discapacidad. Homogeneizante porque al establecer clasificaciones, oculta las diferencias sociales, económicas, culturales de las propias personas diferentes/discapacitados y discriminadora porque si bien protege a las personas con discapacidad, excluye a otros sujetos de su campo de acción (Elder y Cobb en Aguilar, 1992:27).

La política oficial y las regulaciones jurídicas se establecen a partir de la normatividad existente en cuanto a la inclusión social se refiere. Es evidente que se enmarcan diferencias desde lo social a través de preceptos arraigados en la memoria de los miembros de los colectivos que delinean su conducta ante aspectos que se salen de la cotidianidad, determinando que la capacidad y la ejecución funcional en los diversos ámbitos de la vida de los sujetos conllevan situaciones de exclusión social y falta de equiparación de oportunidades en su desarrollo de ciudadanía plena. El estigma es discurso, un lenguaje de relaciones humanas que pone en relación el "yo" con el "otro", el "normal" con el "anormal", el "sano" con el "enfermo", el "fuerte" con el "débil", la "capacitada" con la "discapacitada". Contiene todas aquellas oposiciones excluyentes y dicotómicas que nos permiten trazar los límites seguros de lo aceptable, lo permisible, lo deseable, aplacando así nuestros propios miedos y

\footnotetext{
${ }^{4}$ Dicho estudio se enmarca dentro del Trabajo de Investigación final para la obtención del título de Master en "Género, Identidad y Ciudadanía" de la Universidad de Cádiz.
} 
fobias respecto a la enfermedad, la muerte, el deterioro, la locura, la violencia y el caos. Las tácticas de separación nos permiten decir que una persona es gente, una de nosotros, y que aquella otra es "otra". Erving Goffman (1963) establece que cuando lo "normal" se encuentra por primera vez con lo "otro" estigmatizado se produce una escena sociológica primordial, un momento especial en que la economía moral que gobierna las relaciones sociales se desenmascara, y la sociedad se manifiesta a sí misma en los fenómenos que repudia, excluye y rechaza. En este sentido, las mujeres han sido construidas por excelencia como "la otra", por lo que, el contemplar a las mujeres con discapacidad implica una identidad configurada por la otredad.

Las instituciones, por el hecho mismo de existir, también controlan el comportamiento humano estableciendo pautas definidas de antemano que lo canalizan en una dirección determinada, en oposición a las muchas otras que podrían darse teóricamente. Importa destacar, como lo indican sociólogos como Peter Berger y Thomas Luckmann (1967), que este carácter controlador es inherente a la institucionalización en cuanto tal, previo o aislado de cualquier mecanismo de sanción establecido específicamente para sostén de una institución (Berger y Luckmann, 2008: 74). Un mundo institucional, pues, se experimenta como realidad objetiva, tiene una historia que antecede al nacimiento del individuo y no es accesible a su memoria biográfica. Esta historia de por sí, como tradición de las instituciones existentes, tiene un carácter de objetividad.

La persona con discapacidad se inscribe en un campo de referencia regulado por la lógica de la institucionalización: para el pleno reconocimiento de su condición de "persona con discapacidad", reconocimiento necesario para el acceso a recursos específicos institucionales, ventajas fiscales y determinadas ayudas económicas, necesitará el aval de un diagnóstico clínico que evalúe su condición y grado de discapacidad. Un diagnóstico y una evaluación médicas. "Una vez diagnosticada, la persona será sometida a los diversos procedimientos considerados adecuados a tal condición y grado de discapacidad, lo que supondrá su inclusión en instituciones médicas de tratamiento especializado. $Y$ además, serán evaluadas sus necesidades "especiales", educativas, funcionales, laborales, relacionales, etc" (Ferreira, 2010: 49). Y es aquí donde cobra presencia una de las principales instancias definidoras del campo ${ }^{5}$ de la discapacidad: el Estado. "A través de los sistemas de clasificación que están inscritos en el derecho, los procedimientos burocráticos, las estructuras escolares y lo rituales sociales, el Estado moldea las estructuras mentales e impone principios de visión y división comunes, formas de pensamiento (...) favorece a la vez la monopolización de lo universal por unos pocos y la desposesión de todos los demás así mutilados, en cierto

\footnotetext{
${ }^{5}$ En este estudio se asume y se concibe la discapacidad bajo la noción de campo, siguiendo las aportaciones de Pierre Bourdieu y de las revisiones de las lecturas de la investigación de $\mathrm{M}^{\mathbf{a}}$ Soledad Torres Dávila (2004). Asumirla en este sentido significa concebir la discapacidad, en tanto que campo científico y político, en un sentido relacional. Pierre Bourdieu sostiene que un campo es un espacio social, un microcosmos, un universo, un espacio práctico de la existencia cotidiana, que de acuerdo a leyes propias son relativamente autónomos (Bourdieu, 1992). Como indica M ${ }^{a}$ Soledad Torres Dávila (2004), la discapacidad como campo hace referencia a una conjunto de relaciones, entendidas como las determinaciones que a partir de una propia lógica definen, sujetos, posiciones y disposiciones o actitudes, esquemas, prácticas y discursos (2004: 19).
} 
modo, en su humanidad" (Bourdieu, 1997: 105-108). La discapacidad es una de las categorías posibles dentro del sistema de clasificaciones imperantes. Consideramos que el Estado juega un papel central en la reducción discursiva de la discapacidad al déficit individual, y en tanto que produce la clasificación, reproduce las condiciones para que tal demarcación se sostenga y legitime. Las instituciones especializadas en el tratamiento de la discapacidad son de carácter público, o bien perceptoras de subsidios públicos, puesto que está reconocido formalmente el supuesto derecho de las personas con discapacidad a la igualdad de oportunidades y, dada su condición, se asume que el Estado ha de facilitarles las herramientas de las que ellas mismas no disponen. La ética (neo)liberal de la igualdad de oportunidades en las sociedades meritocráticas, competitivas y que se caracterizan por el auge de la lógica del capitalismo flexible ${ }^{6}$, tiene implicaciones realmente falaces. $\mathrm{Si}$, por una parte, esta ilusión que permite creer que con el suficiente esfuerzo cualquier persona puede superarse, oculta en cierta medida el carácter estructural de las desigualdades sociales. Por otra parte, entre la formalidad de ese reconocimiento y la practicidad de su ejecución se abre el espacio "real" en el que se gesta y reproduce el habitus de la discapacidad (Ferreira, 2010: 49). El Estado y las instituciones dependientes de él aplican todo un conjunto de técnicas de adiestramiento corporal cuyo objetivo es reducir lo máximo posible la desviación respecto de la norma previamente diagnosticada. En un sentido amplio, este adiestramiento implica: fisioterapia, actividades deportivas, prótesis, adecuación laboral, educación especial, etc (lbid). Sus representaciones y sus prácticas son las que configuran el campo en el que se inscriben las personas con discapacidad. Bajo el presupuesto de un cuerpo defectuoso, desviado objetivamente de la norma de salud y social, las prácticas de profesionales delimitan un sentido propio que articula la lógica del campo: ese cuerpo, potencialmente curable y ajustable, y limitado a las condiciones presupuestas de la norma de salud debe ser tratado siempre con la intención de reducir lo máximo posible su desviación. La recurrente lógica de las revisiones y las evaluaciones periódicas, de las preguntas y las pruebas de habilidad periódicas, de trámites burocráticos infinitos y peregrinaciones administrativas... son un escenario en el que se tienen que desenvolver cotidianamente muchas personas con discapacidad que necesiten acceder a ciertos recursos, en gran medida mujeres y con una posición socio-económica definida por la desigualdad en la estructura socio-económica. Es también el Estado la entidad privilegiada para transformar las relaciones arbitrarias en legítimas, funcionando como vehículo para instalar en el "sentido común", en los discursos científicos, en las prácticas profesionales e institucionales, un modo de comprensión de la discapacidad (Rosato et al., 2009: 100).

\footnotetext{
${ }^{6}$ Entiendo este concepto basándome en la obra del sociólogo Richard Sennet, quien lo aborda en La corrosión del carácter. Las consecuencias personales del trabajo en el nuevo capitalismo (2000). Esta obra indaga sobre el impacto de la flexibilización laboral en la formación de la personalidad y en la desarticulación de lazos sociales. Con "capitalismo flexible" se refiere a un sistema que es algo más que una mera variación sobre el que conocimos como "capitalismo industrial-moderno". El capitalismo flexible desestructura el tiempo y el espacio social. El acento se pone en la "flexibilidad", concepto tan de moda en nuestro contexto actual, donde a las trabajadoras/es se les pide un comportamiento ágil, que estén abiertos al cambio, que asuman un riesgo tras otro, y que dependan cada vez menos de los procedimientos y los reglamentos, es esa perspectiva "del emprendedor" que en la actualidad está en boga en los discursos de la clase política y empresarial.
} 


\subsection{La regulación de los límites de pertenencia y las políticas demarcatorias de la discapacidad... ¿Quiénes dis-capacitan?}

Las políticas públicas de reconocimiento de la discapacidad producen en sí misma al colectivo de los discapacitados, creando las características que determinan la inclusión y la exclusión de tal colectivo y sus límites de pertenencia. Tanto en la legislación como en el diseño de planes y programas, en las medidas de políticas públicas, se elude pensar en los procesos de producción de la discapacidad fuertemente anclados en la desigualdad, ya que se relaciona esta desventaja a la naturalización del déficit como problema individual de los sujetos que la padecen. Un análisis que intente desentrañar ciertos mecanismos de producción de alteridad debe necesariamente poner en problematización las políticas sociales "específicas" en discapacidad y su capacidad de producción y reproducción de la violencia simbólica ${ }^{7}$ y, por tanto, de imponer la categoría de "otro".

Como indican los análisis de Rosato et al (2009), un elemento clave en relación con la dominación es la aparición del Estado moderno. Desde entonces el Estado posee una situación privilegiada para la producción de sentido en general y particularmente en el ámbito de la discapacidad, a partir de delimitar un conjunto de personas a través de políticas sociales específicas que, lejos de ser amplias, se centran cada vez más en la desigual distribución de las riquezas. Desde estas políticas, el Estado compensa a los que no han elegido ser como son y opera el mecanismo de "los merecedores", donde el discurso moral se mezcla con el discurso jurídico y médico (Rosato et al,. 2009: 101). La discapacidad se puede entender como resultado de complejos procesos de naturalización y encubrimiento de la desigualdad estructural y la exclusión que ésta produce. Es el Estado "en tanto modo de dominación que condensa casi monopólicamente la legitimación y, de manera más velada, la producción de sentido el que actúa en esos complejos procesos interviniendo en y sobre las relaciones sociales" (Ibid). La clave de esta imposición no está en las mismas teorías de la discapacidad sino en el Estado, y más concretamente, en el modus operandis de sus instituciones y en el despliegue estratégico de sus políticas y administración pública. Estas políticas se delinean a partir de una conceptualización biologicista fundada en el modelo médico de la discapacidad. El Estado es el agente que desde diversos ámbitos y acciones, prácticas o políticas, genera dominación y opera decisivamente en la producción y la reproducción de sentidos. "Es en este proceso de construcción de sus políticas que el Estado vuelve sobre las teorías disciplinares legitimándolas y constituyendo nuevas relaciones sociales y, por ende, nuevas clasificaciones" (Rosato et al., 2009: 10).

En el Estado español estas políticas son importantes por el significado de las prácticas asociadas al "diagnóstico" de discapacidad y el certificado oficial, ya que esto se vuelve un paso necesario e imprescindible para la entrada a los programas y a las políticas sociales. Este dispositivo funciona asignando identidad y constituyendo al grupo de los que son, ahora por definición oficial

\footnotetext{
7 Tomo el concepto "violencia simbólica" de Pierre Bourdieu por ser un concepto que me permite visibilizar, en palabras del autor, "esa violencia amortiguada, insensible e invisible para sus propias víctimas, que se ejerce esencialmente a través de los caminos puramente simbólicos de la comunicación y del conocimiento o, más exactamente, del desconocimiento, del reconocimiento o, en último término, del sentimiento" (1998: 11-12).
} 
jurídica y administrativa, discapacitados. La Administración Pública se torna en productora y dotadora de atributos y rasgos de pertenencia, que reconoce y demarca al mismo tiempo un colectivo, asignando los límites de pertenencia de "capacitados/discapacitados". Las políticas específicas siguen estando sostenidas y legitimadas por modos hegemónicos de entender la discapacidad como fenómeno exclusivamente emplazado en el orden biológico y como cuestión exclusivamente individual, siendo modos de producción de discapacidad y discapacitados reforzado por efecto de ideología de la normalidad.

La clasificación por patologías o deficiencias tiene mucho sentido para el ámbito médico a la hora de clasificar y determinar tratamientos para curar o rehabilitar una determinada deficiencia orgánica. Estas clasificaciones resultan útiles desde la perspectiva médica, por tanto, al dejar atrás el modelo rehabilitador no se trata de eliminarlos, sino de contextualizarlo con la parte social y estructural de la discapacidad. Se trata, como indica Arnau Ripollés (2004), de reducir al ámbito médico lo que es del ámbito médico y no mezclarlo con la realidad y problemática social de las personas con discapacidad. El uso indebido y eclipsante de la clasificación médica como herramienta de diseño de políticas y acciones sociales da lugar a una gran confusión y a unas políticas sociales incoherentes en las que el paradigma médico domina por completo.

En la actualidad, en el Estado español el reconocimiento oficial de la posesión de una "discapacidad" implica la obtención de un certificado de "grado de discapacidad" emitido en función de un dictamen de un equipo compuesto por profesionales de la medicina, la psicología y el trabajo social. Esto está regulado en virtud del Real Decreto 1856/2009, de 4 de diciembre, de procedimiento para el reconocimiento, declaración y calificación del grado de discapacidad, por el que se modifica el Real Decreto 1971/1999, de 23 de diciembre, de procedimiento para el reconocimiento, declaración y calificación del grado de minusvalía. En la normativa se establece que la ley 39/2006, de 14 de diciembre, de Promoción de la Autonomía Personal y Atención a las Personas en situación de dependencia, en su disposición adicional octava establece que "las referencias que en los textos normativos se efectúen a minusválidos y a personas con minusvalía, se entenderán realizadas a personas con discapacidad". Así mismo, establecía que las disposiciones normativas elaboradas por las Administraciones Públicas desde entonces debían utilizar los referidos términos.

La OMS reconoció al inicio de la revisión de la Clasificación Internacional del Funcionamiento, de la Discapacidad y de la Salud (CIF-2001), que los términos utilizados pueden estigmatizar y etiquetar, por lo que tomó la decisión de abandonar el término "minusvalía", debido a su connotación peyorativa y de utilizar en su lugar el de "discapacidad", como término genérico que incluye déficits, limitaciones en la actividad y restricciones en la participación. Según la $\mathrm{CIF}$, el concepto de "discapacidad" se refiere a los aspectos negativos de la interacción entre individuo con una determinada "condición de salud" y sus factores contextuales (ambientales y personales). Con esta fundamentación se actualiza el Real Decreto 1971/1999, para regular el reconocimiento administrativo de la situación de discapacidad. En este sentido, únicamente se reemplaza el término de "grado de minusvalía" por el de "grado de discapacidad", y las referencias que se realizaban hasta ahora a la 
"discapacidad" se sustituyen ahora por "limitaciones en la actividad", y, a su vez, todas las referencias que hasta el momento se venían realizando en el Real Decreto al "grado de discapacidad" quedan sustituidas por "grado de las limitaciones en la actividad"8. Así pues, podemos recordar que si bien en las últimas décadas ha habido una transformación terminológica y algunas matizaciones conceptuales importantes, los presupuestos de fondo se mantienen en las normativas. Recordemos el Real Decreto 1723/1981, de 24 de julio, sobre reconocimiento, declaración y calificación de las condiciones de subnormal y minusválido, dictado al amparo de lo dispuesto en el Real Decretoley 36/1978, de 16 de noviembre, de Gestión Institucional de la Seguridad Social, la Salud y el Empleo, que procede a la unificación en el Instituto Nacional de Servicios Sociales (INSERSO) de las competencias y las facultades en orden al reconocimiento, la declaración y la calificación de la condición de minusválido ${ }^{9}$. Por otro lado, en la Ley General de la Seguridad Social, aprobada por el Real Decreto legislativo 1/1994, de 20 de junio, establece la necesidad, para ser beneficiarios de la pensión de invalidez en su modalidad no contributiva y protección familiar por hijo/a a cargo minusválido/a, que la persona esté afectada de un determinado grado de minusvalía. El requisito de grado de minusvalía ha de establecerse aplicando los baremos contenidos en la Orden del Ministerio de Trabajo y Seguridad Social de 8 de marzo de 1984. Asimismo, se establece que los baremos serán objetos de actualización mediante Real Decreto con el fin de adecuarlos a las variaciones en el pronóstico de las enfermedades, a los avances médicos-funcionales y a la aparición de nuevas patologías. Así pues, el Real Decreto 1856/2009 vigente en la actualidad, establece como objeto "la regulación del reconocimiento de grado de discapacidad, el establecimiento de nuevos baremos aplicables, la determinación de los órganos competentes para realizar dicho reconocimiento y el procedimiento a seguir, todo ello con la finalidad de que la valoración y la calificación del grado de discapacidad que afecte a la persona sea uniforme en todo el territorio del Estado, garantizando con ello la igualdad de condiciones para el acceso del ciudadano a los beneficios, derechos económicos y servicios que las organizaciones públicas otorguen" (Artículo 1. Objeto).

Para la calificación del grado de discapacidad se evalúan "tanto las limitaciones en la actividad que presente la persona, como, en su caso, los factores sociales complementarios relativos, entre otros, a su entorno familiar y situación laboral, educativa y cultural, que dificulten su integración social" (Artículo 4. Grado de discapacidad). Los órganos técnicos y los equipos de valoración para la emisión del dictamen técnico-facultativo estarán formados al menos por un/a médico/a, psicólogo/a y trabajador/a social.

En cuanto a los baremos utilizados para la valoración del grado de discapacidad se indica que los baremos establecen la evaluación de las consecuencias de la enfermedad, de acuerdo con el modelo propuesto por la Clasificación Internacional de Deficiencias, Discapacidades y Minusvalías de la OMS. Así, se establece la definición de discapacidad como "la restricción o

\footnotetext{
${ }^{8}$ Sirva como aclaración que en el Real Decreto 1971/1999 que es actualizado se utilizaban de manera indistinta en ocasiones, confusa y ambigua, en otras, los términos de "minusvalía", "discapacidad", "incapacidad".

${ }^{9}$ Los subrayados son añadidos.
} 
ausencia de la capacidad para realizar una actividad, en la forma o dentro del margen que se considera normal para un ser humano" (Anexo 1, Introducción).

Para declarar los grados de discapacidad, el Real Decreto establece las deficiencias y las limitaciones que se consideran que afectan al desarrollo de las actividades de la vida diaria. La conceptualización de "actividades de la vida diaria" es tomada de la Asociación Médica Americana en 1994, por la que se establece la siguiente definición: "son las actividades que se refieren al autocuidado, comunicación, actividad física, función sensorial, funciones manuales, transporte (capacidad para utilizar los medios de transportes), función sexual, sueño, actividades sociales y de ocio"10.

Una consideración al margen merece la valoración de la enfermedad mental que se realiza de acuerdo con los grandes grupos de trastornos mentales incluidos en los sistemas de clasificación "universalmente aceptados", como son la CIE-10 y el DSM- IV ${ }^{11}$. Teniendo como referencia estos manuales, los grandes grupos psicopatológicos susceptibles de valoración son: trastornos mentales orgánicos, esquizofrénicos y trastornos psicóticos, trastorno del estado de ánimo, trastorno de ansiedad, adaptativos y somatomorfos, disociativos y de personalidad. En este sentido, el Real Decreto 1856/2009 establece que se entiende por "trastorno mental" el "conjunto de síntomas psicopatológicos identificables que, interfieren el desarrollo personal, laboral y social de la persona, de manera diferente en intensidad y duración". Así pues, la valoración de la discapacidad que un trastorno mental conlleva, se realiza a partir de: la disminución de la capacidad del individuo para llevar a cabo una vida autónoma, la disminución de la capacidad laboral y el ajuste a la sintomatología psicopatológica establecida por el DSM- IV.

\footnotetext{
${ }^{10}$ Los grados de discapacidad que pueden ser declarados son los siguientes (Anexo $1 \mathrm{~A}$. Capítulo I):

GRADO 1: discapacidad nula. Los síntomas, los signos o las secuelas son mínimos y no justifican una disminución de la capacidad de la persona para realizar las actividades de la vida diaria (en adelante A.V.D).

GRADO 2: discapacidad leve. Los síntomas, los signos o las secuelas justifican alguna dificultad para llevar a cabo las A.V.D, pero son compatibles con la práctica totalidad de las mismas.

GRADO 3: discapacidad moderada. Existe una disminución importante o imposibilidad de la capacidad de la persona para realizar algunas de las A.V.D, siendo independiente en las actividades de autocuidado.

GRADO 4: discapacidad grave. Existe una disminución importante o imposibilidad de la capacidad de la persona para realizar la mayoría de las A.V.D, pudiendo estar afectada alguna de las actividades de autocuidado.

GRADO 5:, discapacidad muy grave. Hay una imposibilidad para la realización de las A.V.D.

${ }_{11} \mathrm{La}$ CIE-10 es la Clasificación Internacional de Enfermedades, décima edición, que determina la clasificación y codificación de las enfermedades y una amplia variedad de signos, síntomas, anormalidades y causas de enfermedad. EI DSM-IV es el Diagnostic and Statistical Manual of Mental Disorders (Manual Diagnóstico y Estadístico de los Trastornos Mentales) de la Asociación Americana de Psiquiatría, en cuarta edición vigente, que establece una clasificación de los trastornos mentales y proporciona descripciones de las categorías diagnósticas. Ya está prevista la publicación del DSM-V para el año 2013.
} 


\section{LA INFLUENCIA DEL GÉNERO EN LA CATALOGACIÓN DE LAS DISCAPACIDADES EN LAS MUJERES}

Es importante tener en cuenta todo lo anteriormente analizado, ya que tal y como señala el resumen analítico del Informe de la OMS de 2009, Las mujeres y la salud. Los datos de hoy, la agenda de mañana ${ }^{12}$, los "trastornos mentales", y, en particular, la depresión y la ansiedad, son una causa importante de discapacidad en las mujeres de todas las edades. Si bien las causas de estos trastornos pueden variar de una persona a otra, en las mujeres son factores contribuyentes la baja condición socioeconómica, la carga de trabajo que sobrellevan y la violencia de que pueden ser objeto (Caballero, 2012: 329). Es fundamental visibilizar que el género tiene una importante incidencia en la salud mental, ya que determina el poder diferencial y el control que los hombres y las mujeres tienen sobre los factores socioeconómicos de sus vidas, su posición y condición social, el modo en que son tratados dentro de la sociedad y su exposición a riesgos específicos para la salud física y mental. En el Estado español no existen datos acerca de la incidencia de situaciones de malestar psicológico entre las mujeres con discapacidad, concretamente. A lo sumo, la Estrategia en Salud Mental del Sistema Nacional de Salud 2009$2013^{13}$ informa que la prevalencia de mala salud mental es mayor entre las mujeres de clases sociales más desfavorecidas. Cuando hablamos de salud mental de las mujeres con discapacidad no nos referimos necesariamente a la existencia de una "enfermedad" o "trastorno", sino más bien a la presencia de un malestar que puede ser originado precisamente por las situaciones de discriminación que estas mujeres sufren en su día a día. Sirva como ejemplo lo que plantea Isabel Caballero (2012) refiriéndose a los "modelos de corporeidad femeninos claramente excluyentes, el acceso vetado a servicios y recursos, derechos, sexuales y reproductivos negados, la exclusión del mercado laboral, los episodios de violencia que pasan desapercibidos por la sociedad, etc, son realidades que han contribuido a conformar una subjetividad femenina que las sitúa en espacios liminales donde operan numerosos mecanismos de disciplinamiento y represión social" (Caballero, 2012: 329-330). Todo esto puede llegar a tener un impacto negativo en la autopercepción y en los estados mentales de las mujeres con discapacidad y desencadenar confusión, insatisfacción y frustración en su identidad y en su desarrollo vital, siendo todas estas situaciones derivadas de los roles socialmente construidos en el marco de un sistema patriarcal y normalista. Son por este tipo de situaciones por las que las normativas, apoyándose en los discursos biomédicos y psiquiátricos, etiquetan en mayor medida a las mujeres como patológicas y "trastornadas mentales".

La idea de que el cruce de los factores de género y discapacidad son la causa de una discriminación, no únicamente "doble", como si tan sólo fuera una cuestión sumatoria de variables fragmentadas, sino una discriminación compleja, única y estructural, no encaja en el lenguaje político y jurídico. Se puede ver cómo en las normativas que se ocupan de regular este ámbito se hacen continuas referencias a las mujeres con discapacidad de manera fragmentada y estableciéndose en un bloque que de manera repetitiva en el

\footnotetext{
12 http://whqlibdoc.who.int/hq/2009/WHO_IER_MHI_STM.09.1_spa.pdf

13 Estrategia en Salud Mental del Sistema Nacional de Salud 2009-2013. Sanidad 2011. Ministerio de Sanidad, Política Social e Igualdad Pág. 17, cit. por Caballero, 2012: 330.
} 
discurso se asemeja a las niñas o a los menores y al perteneciente a las "otras mujeres" donde se incluyen una gran variedad de situaciones que componen el bloque de los márgenes (mujeres migrantes, discapacitadas y enfermas, mayores, prostitutas... como si se tratase de variables estancas). Tanto el género como la discapacidad, han sido factores considerados aisladamente en la elaboración y la gestión de políticas de igualdad, lo que ha impedido un progreso mayor en el análisis de las formas en que interactúan estos dos factores de discriminación.

\section{REALIDADES ENCONTRADAS: EN TORNO A LAS VIVENCIAS DE SER CATALOGADAS}

A continuación se presentan hallazgos relevantes en torno al análisis de la catalogación de la discapacidad atravesada por el dispositivo de género, la vivencia de la discapacidad en sí misma, y los procesos vividos en torno a la gestión psicológica y social que supone la toma de conciencia de la discapacidad.

\section{1. Los efectos perversos de la catalogación oficial: entre el reconocimiento de la discapacidad como derecho y el estigma de la minusvalía}

La toma de conciencia de una discapacidad es un proceso complejo en el que intervienen diversos factores. En primer lugar, es importante aclarar que se trata de una toma de conciencia de alguna manera impuesta, es decir, las mujeres con discapacidad se dan cuenta de su discapacidad a raíz de un proceso de catalogación en el que intervienen profesionales de la medicina, de la psicología y de la administración. Una persona puede ser catalogada como discapacitada debido a determinadas enfermedades o afecciones orgánicas que conllevan desviarse de los roles sociales de funcionamiento, y debido a accidentes coyunturales que alteran el estado anterior de normalidad del cuerpo y de la salud. Es por ello, que la discapacidad produce un impacto a través del cual se toma conciencia de un nuevo estado, de una nueva concepción del yo, y de unas nuevas características. A continuación, se muestra cómo las informantes relatan el impacto que tuvo tomar conciencia de la categoría discapacidad, que el entorno le reconociera como discapacitada y el sentido que le dan al diagnóstico administrativo que supone el reconocimiento del grado de discapacidad, a través de diferentes casuísticas. Por un lado, había mujeres cuya catalogación había sido sobrevenida en un determinado momento de su vida, lo que supuso un punto de inflexión:

"Yo mi discapacidad la verdad es que no sé exactamente desde cuando la tengo, no lo sé, o sea yo a partir del 99 que me empezaron a hacer pruebas y eso se supone que, que fue cuando me lo descubrieron, pero el certificao me lo saqué hace un par de años a raíz además del trabajar aquí vamos, porque yo antes estaba super desinformada de esta historia y el oftalmólogo me había dicho que, que bueno que fuera a la ONCE que me informara, pero la verdad es que me daba un poco de reparo y hasta que bueno, que no empecé porque yo entré aquí sin el certificao y a raíz de estar trabajando aquí pues ya bueno pues no sé parece que te informas un poco más y no sé, lo ves desde otro 
punto de vista y me dio como menos miedo y menos reparo el tramitarlo, y entonces lo tengo hará un par de años más o menos" (37 años, DF, 33\%) ${ }^{14}$.

Esta toma de conciencia de la discapacidad supone reiniciar un proceso de identificación incluyendo un nuevo factor estructurante, la discapacidad. Así, las mujeres tienen que reconfigurar su identidad a una nueva realidad que antes era desconocida. En este proceso de identificación, la construcción de género también juega un papel importante sobre las mujeres con discapacidad. Esta situación puede dificultar los procesos de identidad de género o la adaptación a lo que se espera socialmente de mujeres y de hombres, así como la identificación con la correspondencia de sexo-género al que se pertenece en el ejercicio de los roles asignados desde el sistema patriarcal.

Por otro lado, otras mujeres habían interiorizado desde pequeñas la discapacidad, en las que se incorpora la categoría "desde el nacimiento":

"Ahora mismo ya en mi relación y el cómo afrontarlo lo tengo bastante asumido porque como lo tengo desde nacimiento pues también mi familia, también me ha aportao bastante en ir sintiéndome integrada en la sociedad ¿no?" (39 años, DF, 33\%).

"Yo en mi caso mi discapacidad es desde que nací y vamos yo era consciente de que tenía discapacidad, de mi limitación y demás, pero vamos nunca me animé a pasar por el centro de valoración. Y ya fue de mayor una vez que tenía mis estudios terminaos y demás pues la familia comentándome pásate que lo vas a pasar, porque yo sabía que lo pasaba bien vamos que me iban a dar discapacidad, por el tema de los beneficios y demás que pudiera tener o en temas de estudios y demás, y lo tengo desde hace poco" (44 años, DF, 33\%).

El proceso de valoración oficial que valora el grado en el que se está discapacitada se torna en crucial, en cuanto aporta significados sociales importantes, en la percepción de cómo estas mujeres se ven a sí mismas:

"Bueno a mí, nunca es agradable el proceso de la valoración pero ya cuando me llega la carta a casa y que pone el 73 y dices jostia ¿tanto?! Y en verdad me quedé en plan de... ¿tanto? ¿tantísimo es?" (25 años, DS, 73\%).

"Es que tú ves el 75 o el 73 y dices juf! Yo que sé es un shock psicológico ¿sabes? De decir, pero bueno que en realidad lo asumes lo que pasa que el momento de verlo reflejao en un papel es complicao vamos" (37 años, DS, $75 \%)$.

"Pues yo creo que a mí me influyó, o sea fíjate es algo de toda la vida y totalmente se supone que asumío, pero el tener el certificao yo pienso que a nivel personal también me... o sea no es que hiciera un antes y un después y que yo me transformara por ese certificao, pero sí que me sentía que pertenecía a un grupo que antes... hombre en tu mente estaba que pertenecías pero no te sentías. Es que no sé, yo sí que noté un gran cambio, de hecho yo me lo saqué pa presentarme a las oposiciones y me presenté. Yo iba con todas mis amigas y yo tuve que ir a un tribunal a parte, en una localidad a parte y yo

\footnotetext{
${ }^{14}$ Las entrevistan han sido codificadas preservando el anonimato de las mujeres entrevistadas y atendiendo a las características de edad, tipo de discapacidad y grado de discapacidad catalogado. Así, los tipos de discapacidad se identifican de la siguiente forma: DF (Discapacidad Física), DS (Discapacidad Sensorial) y DP (Discapacidad Psíquica).
} 
no lo viví bien, de hecho recuerdo en el examen no estar... yo no digo que eso fuera lo que marcara el cómo me saliera el examen, pero que yo no recuerdo bien el hecho de presentarme por discapacidad. Lo viví más como una desventaja que como una ventaja, por lo menos lo sentí así ¿no? [...] Pero en aquel momento a mí me fastidió que por presentarme por discapacidad todas mis amigas fueran a un sitio y yo tuviera que desplazarme la noche anterior a otro sitio, tener que no sé cuanto en el tribunal. Yo no recuerdo que haya una experiencia buena y eso que se supone que tenía mi discapacidad y que llevaba toda mi vida con ella, pero que yo sí recuerdo ese período así que no, que me afectó vamos" (39 años, DF, 50\%).

En este sentido, se plasma la influencia que tiene este tipo de catalogaciones en los comportamientos y en las experiencias en la medida en que la autoridad que representa este tipo de etiquetaje construye identidad e incorpora en el sujeto una categoría que socialmente es estigmatizante, que también influye en cómo se presentan ante los demás:

"¿Por qué tengo que contarle a to el mundo?, si la discapacidad si el decir que tú tienes alguna limitación no tiene ninguna connotación negativa daría igual contarlo o no contarlo, el problema es que cuando tú sientes que al contarlo la mirada del otro hacia a ti cambia, y a mí no me gusta sentir esa mirada. Por lo menos a mí no me gusta que me miren de esa manera" (19 años, DF, 50\%).

"Es incómodo, yo en mi caso además el tema de mi discapacidad lo saben aquí porque no me queda más remedio y en mi casa, pero ni en el resto de mi familia, o sea que no sean mis padres y mi hermano, no lo saben ni mis amigas ni nadie, o sea porque no sé es una cosa que tampoco tengo por qué ir poniéndome un cártel, ni explicándoselo a nadie pero que, que no lo sabe nadie vamos" (37 años, DS, 75\%).

En el Estado español la legislación a través de la que se regula la catalogación y el reconocimiento oficial del grado de discapacidad produce significados en el campo de la discapacidad que se inscriben en los propios discursos y vivencias de las mujeres. También esta regulación se vuelve un paso necesario e imprescindible para la entrada a los programas y a las políticas sociales dirigidas a los discapacitados ${ }^{15}$. La Administración Pública y el Estado se tornan en productores de atributos y rasgos de pertenencia, que reconoce y demarca, al mismo tiempo, un colectivo, estableciendo así quiénes son; con ello, inevitablemente, se está asignando, como decíamos anteriormente, unos límites de pertenencia.

Así relataban las mujeres entrevistadas al ser preguntadas por el sentido y la utilidad que tiene para ellas el certificado que las identifica como discapacitadas en un determinado porcentaje. En la mayoría se produce un análisis en el que convergen varios significados, por un lado, las mujeres perciben que ser identificadas por una categoría como la de discapacitada es estigmatizante socialmente pero, por otro lado, en la toma de conciencia de la desigualdad en la que se reconocen, identifican que es necesario tener ese certificado para acceder a ciertos "beneficios" compensatorios que el propio sistema que cataloga tiene previstos:

\footnotetext{
${ }^{15}$ Lo indico en masculino intencionadamente, ya que en el imaginario social y jurídico el colectivo de "los discapacitados" es un bloque homogéneo, neutro y asexuado.
} 
"Yo creo que aquí hay dos caras de una misma moneda, aquí está una parte que es la que digamos...es bueno que nos reconozcan la discapacidad administrativamente porque ello nos hace partir de una diferencia con el resto de las demás personas, entonces si queremos ser iguales tú sabes que no podemos ser iguales si no...si la diferencia no se trabaja antes ¿no? porque partir de la misma para llegar a una meta tenemos que partir siempre [...] Entonces empuje administrativo viene bien, que sería esa acción positiva ¿no?, acción positiva y no discriminación positiva, acción positiva para ponerte ahí y yo creo que esa parte viene bien. Pero ya todo lo demás, que no sea a ese nivel administrativo, todo lo demás es terrible. Es terrible pasar por ahí, terrible creértelo tú de que realmente estás discapacitada, creerte tú... porque el que uno se crea que no es válido para algo te hace...te hunde, te hunde personal y profesionalmente" (51 años, DF y DP, 45\%).

"Yo creo que ayuda, hay alguna gente que según que no tienen asumío su discapacidad y dicen que le perjudican porque realmente no... pueden sentir un rechazo. Pero también, no es culpa nuestra sino porque a la empresa a la que van no están concienciadas y no tienen ni la explicación correcta de lo que significa contratar a una persona con discapacidad, ni cuáles son los beneficios, ni tampoco le da la oportunidad a las personas con discapacidad de hacerlo, pero que hay una... ies como todo! te encuentras de todo, a lo mejor te encuentras a personas sin discapacidad y tampoco dan la talla en su puesto de trabajo ¿eh? El que tiene mayor discapacidad y lo tiene a lo mejor que es más revisable, yo veo que es lo correcto que tenga que hacerlo que se tenga que dedicar también a hacerse esas valoraciones y esas revisiones porque hay enfermedades que realmente pues... no es que vayan mejorando, pero a lo mejor si es de una operación o lo que sea y te lo dieron con eso pues bueno también se tiene que ir mejorando porque hay gente que... es que también hay mucho fraude también y es lógico cuando llega una época que tiene que revisarse y se tiene que lleva un control" (39 años, DF, 33\%).

La convergencia de estos significados también se da en el caso de contemplar que el reconocimiento, por parte del sistema jurídico y administrativo, de la discapacidad se contemple como un derecho por el propio movimiento asociativo de la discapacidad, ya que implica el reconocimiento de que no se está en igualdad de oportunidades y el derecho a tener ciertas prestaciones sociales que se considera que un colectivo social en desventaja debe tener en el marco de un Estado de Bienestar democrático. Así lo expresaba un de las presidentas de las asociaciones de personas con discapacidad entrevistadas:

"El grado de discapacidad más o menos está reconocido en ciertas discapacidades de forma más o menos adecuada. Como todo en esta vida se puede producir algunos disfuncionamientos pero el problema está, más que en el grado de discapacidad pa la discapacidad motórica o intelectual o de sordera o de ceguera, está en ciertas discapacidades orgánicas que no se ven o son por ejemplo enfermos renales, los enfermos de enfermedades raras que todavía... o las de fibromialgia que no se reconoce la discapacidad porque no aparecen en los análisis claramente no aparecen los síntomas, los efectos. Entonces hay una serie de discapacidades que no son valoradas adecuadamente porque no se tienen instrumentos de reconocimiento y también porque se estima que la discapacidad hay que medirla a partir de que seas 
capaz de hacer o no las digamos las actividades propias de las actividades cotidianas, si eres capaz de asearte, de comer, de desplazarte. Claro hay muchas personas que tienen discapacidades graves que sí pueden hacer eso y no están suficientemente reconocidas, pero en líneas generales, los motóricos y otras discapacidades son reconocidas en sus justos términos. El problema no está ahí el problema está en que las prestaciones que se ofrecen a las personas que tienen discapacidad, si no están adecuadamente cuadradas no son las mismas si se te reconocen unos grados que si se te reconocen otros, y sobre todo el reconocimiento en general, legislativo a la discapacidad es correcto hemos luchao mucho para él lo cual no quiere decir que los baremos, que las medidas que se hacen para calificarnos no tengan que ser actualizadas continuamente porque la discapacidad también evoluciona y si entendemos por discapacidad las dificultades que una persona tenga para desarrollar su vida diaria, ésta varía mucho en función del entorno, en función del tipo de enfermedad discapacitante que padezcas claro" (DF, 86\% ${ }^{16}$ ).

En esta misma línea, algo que se torna en significativo por su implicación en la propia vida e identidad es el proceso a través del cual se valora a las mujeres para diagnosticar el grado de discapacidad que padecen. Es una experiencia insignificante para la administración que lo convierte en un puro trámite burocrático, pero sin embargo, una experiencia incómoda y frustrante - y a veces dolorosa- para las mujeres que la recuerdan:

"Agradable no es, en mi caso particular yo no... nadie se portó conmigo de manera desagradable ni me trataron mal ni hicieron nada, pero el que te valoren y te digan hasta qué punto tienes una discapacidad, en qué punto, en qué grado te alejas de la normalidad, es ponerte ahí enfrente de lo que sabes que ocurre pero... Entonces la situación no es agradable" (39 años, DF, 50\%).

"En mi caso, por ejemplo, como he comentao vamos tú sabes eres consciente de la limitación que tienes ¿no? Entonces tú sabes que sí, entonces yo no necesito que me lo den por escrito o que ciertas personas se líen conmigo ahí a estudiarme, entonces claro el trato es muy cordial y... pero claro te están valorando también hasta dónde llegas y hasta dónde no llegas, para que te lo reflejen por escrito cosas que tú ya sabes. [...] Yo entiendo que el tema de la discapacidad nunca es positivo aunque mucha gente crea que es un chollo ¿no? Yo no lo considero así, pero bueno tiene sus ventajas y sus inconvenientes como todo en la vida [...]. Te pueden poner incluso más pegas en otros temas, yo me he presentao a una entrevista de trabajo y no he aportado nada de mi dictamen ni he dicho que tenía discapacidad, y he trabajao sin discapacidad aunque la tuviera reconocía ¿sabes lo que te quiero decir? Entonces te puede ayudar o no te puede ayudar, es que depende" (44 años, DF, 33\%).

Otras mujeres hacían hincapié en el certificado del grado de discapacidad como estigma que incapacita para el desarrollo y la participación en muchos ámbitos sociales, en lo que se refiere a los sentimientos que se generan, tanto en ellas mismas como en el entorno con el que interaccionan:

\footnotetext{
${ }^{16}$ Esta informante no quiso indicar su edad.
} 
"Yo no sé si me hubiesen contratao aquí ${ }^{17}$ porque yo me lo saqué a raíz de... yo terminé un contrato temporal y me dijeron que bueno que les gustaría contar conmigo entonces... entonces fue cuando yo lo tramité y dije bueno pues puede ser una oportunidad ¿sabes? Porque hombre laboralmente la empresa tiene ventajas, que si no lo tuviera no sé si me hubiesen contratao igual. No tengo ni idea pero bueno en mi caso yo creo que me favoreció. Lo que sí que si no fuese... o sea fuera de aquí yo no se si sería capaz de enseñarlo o sea de decir... entrar en un... de presentarlo para solicitar un trabajo. Yo creo que todavía no estoy preparada vamos [...] Yo creo que no lo hubiese tramitao nunca el certificao vamos y si lo hubiese tramitao no lo hubiera usao a la hora de buscar un trabajo ¡no lo hubiese usao seguro!" (37 años, DS, 75\%).

"Hombre, yo he hecho muchas entrevistas y he entregao currículum y sí que lo he presentao lo que pasa es que la gente al ver ya que pone discapacitada piensa que no puedes hacer el trabajo... o yo que sé qué se imaginarán. Yo creo que no lo toman en cuenta, sopesan un poco los beneficios económicos que le supone al empresario, pero claro tú dices este trabajador no lo va a hacer bien y eso no es así" (25 años, DS, 73\%).

Otro de los aspectos más importantes de la catalogación de las discapacidades es el significado que cobra el diagnóstico de una discapacidad psíquica por trastornos mentales. De las 26 mujeres con las que se ha tenido contacto, 14 de ellas tienen una discapacidad múltiple, donde se les suma un grado de discapacidad psíquica en su mayoría derivada de depresiones, ansiedad, y de los llamados trastornos del estado de ánimo. Así respondían algunas de ellas ante la pregunta sobre su tipo de discapacidad:

"Yo el 44, y física y psíquica" (54 años, DF y DP, 44\%).

"Yo el 67, y física y psíquica también" (56 años, DF y DP, 67\%).

"A ver, el porcentaje es el $45 \%$ y de ellos el $35 \%$ es físico y después psíquico porque el físico es lo de la artrosis degenerativa y lo... el psíquico pues por el trastorno distímico, trastorno de la afectividad, depresión distímica que quiere decir que dura más de dos años" (51 años, DF y DP, 45\%).

"Yo tengo física, psíquica, sensorial, el 75 \%" (52 años, DF, DP y DS).

"Yo tengo física y psíquica... el 85\%" (62 años, DF y DP, 85\%).

Las mujeres son en mayor medida categorizadas con respecto a desequilibrios emocionales y psicológicos. Variables influyentes en el bienestar psicológico de cualquier individuo en nuestro contexto actual como puedan ser, procesos estresantes, redes sociales empobrecidas, falta de recursos económicos y sociales, situaciones de violencia, etc, son factores que, en una sociedad patriarcal, son sistemáticamente desfavorecedores para las mujeres. Así, existen más casos de etiquetaje por depresión, ansiedad y otros llamados "trastornos mentales" en mujeres que en hombres, hecho que se tiene que contextualizar en el marco de las condiciones patriarcales y capitalistas existentes. Así relataba una mujer el impacto y el estigma que supuso, en el desarrollo de su vida, el diagnóstico y el etiquetaje de un trastorno mental derivado de una depresión:

\footnotetext{
${ }^{17}$ Trabaja en FEGADI (Federación Gaditana de Personas con Discapacidad).
} 
"Me han añadido un hándicap para encontrar trabajo, porque un ¿trastorno de la afectividad? Es muy grave ¿eh?... y yo creo que yo... en un momento dado tengo que... todavía tengo que indagar quién me lo ha... quién ha sido el que me lo ha visto así porque en dos sesiones, en dos visitas no creo que, bueno en una porque me han valorado dos expertas psicólogas cada una por separao, o sea en diez minutos, no creo que se pueda de repente ver eso y más que nada porque es todo lo contrario, es un perfil que responde totalmente a todo lo contrario a como yo soy, sin embargo, sí que lo veo en mi familia y a lo mejor yo me he contagiao ¿sabes? [...] Hasta hoy pensaba no decirlo porque no he querido... porque sé que es fuerte y que cambia, las personas cambian su forma de actuar contigo cuando saben que... que tienes esa discapacidad [...] Cuando en verdad a lo mejor esa discapacidad que tú tienes es una discapacidad más que nada física que te incapacita para acceder a muchas cosas que pertenecen al ámbito social ¿no?... ¿qué ocurre? Que entonces debido a todo eso es lo que te lleva a tener ese ese... trastorno psíquico, pero que si tú tuvieses solucionao lo que es el ámbito social, en verdad no tendrías por qué caer en esa depresión. Depresión que yo he creído que era, y sigo creyendo que es una depresión normal dentro de un duelo de pérdidas, porque yo he perdido muchas cosas y las he perdido desde el 2007, he ido perdiendo cosas [...] Yo creo que esto no es un trastorno psíquico porque lo tenga una persona que ha nacido, que sea innato ni mucho menos, yo creo que esto es adquirido por las circunstancias del entorno" (51 años, DF y DP, 45\%).

En este mismo sentido que se está exponiendo, hubo muchas mujeres que relataron experiencias vitales traumáticas y dolorosas derivadas de violencia de género, de falta de recursos económicos y sociales, conflictos familiares, frustraciones derivadas de la sobrecarga de obligaciones familiares impuestas y estructuradas por la condición de género y por la vivencia de incapacidades, por las que afirmaban sentirse deprimidas de forma patológica:

"Es que tengo una depresión de caballo [...] Yo la autoestima la tengo por los suelos [...] Yo pensé en dejar al tipo porque nos pegaba, nos maltrataba... a los bebés también... y me fui de la casa" (52 años, DF y DP, 75\%).

"[...] Eso a mi me ha hecho que yo haya estao más de 15 años en tratamiento psiquiátrico, porque ni he tenío ayuda ni nadie que me aconsejara como tenía que llevar todo eso, ahora que yo tenía que ser la fuerte y tuve que estar aquí, y no te vaya aburrí y no esto y no lo otro. $Y$ tener una comida por cojones y bregar con un niño chico y darle de comer a las cuatro de la mañana, to los días con un niño en brazo, y sin consideración ninguna ¿eh?" (62 años, DF, $44 \%)$.

Hay contradicciones importantes entre el discurso hegemónico de la discapacidad y la experiencia de la discapacidad de cada mujer. El discurso de la discapacidad es androcéntrico, lo que implica la invisibilidad de las múltiples variantes de la opresión que viven las mujeres con discapacidad. El proceso de construcción de la identidad de los individuos es una realidad dinámica que se desarrolla por medio de las experiencias intersubjetivas y a lo largo de la vida. En este sentido, existen variables como la discapacidad que tiene una gran incidencia en el proceso de construcción y reconstrucción de la identidad de las mujeres (Shum y Conde, 2009:120). 
A pesar de las definiciones heterodesignadas que se imponen a lo que tiene que significar la discapacidad $y$, en este caso, "ser una mujer con discapacidad", existe agencia y empoderamiento por lo que estas mujeres ven que, a pesar de todas las dificultades impuestas y que por su socialización ellas también construyen, hay una manera de redefinirse. Algo que se ha constatado a lo largo de las entrevistas es que hay un cierto cuestionamiento a la propia idea de lo que significa la normalidad y, por tanto, el "ser normal", a pesar de haber existido una fuerte socialización que incide en la incorporación de las normas y de la norma, entendida como lo que más se repite en el sentido estadístico y lo que se considera mayoritario, que a nivel social se institucionaliza y se aprende como lo natural; lo que es y lo que debe ser. Así se explicaban las informantes:

"Claro la normalidad si tú lo dices teóricamente es todo lo que se ajusta a la norma, el problema es que si la norma es un cuadraito así [hace un cuadrado con las manos] todo lo que se salga de ese cuadraito no es normal, y a lo mejor acaba habiendo más gente fuera de la normalidad que dentro de la normalidad. El problema es cómo se define ese concepto de normalidad porque yo no me siento anormal, yo me siento dentro de la norma, el problema es que tengo que ajustar ciertas cosas" (39 años, DF, 50 \%).

"Lo normal... lo normal entra dentro de la norma ¿no? De lo que la gente considera normal. Para mí normal es todo aquello que tú veas que tu conciencia te lo permite, aquello que es coherente con lo que tú, tu ética y tu moral te dicta, eso para mí es lo normal, lo demás me da igual lo que la gente crea que es normal o no" (51 años, DF y DP, 45\%).

Lo normal funciona como una demarcación de la norma, del patrón establecido. Así, lo normal no es un concepto puramente descriptivo sino prescriptivo, del como tiene que ser. Las definiciones de la normalidad, ajustadas a la norma, son tan exigentes que las mujeres con discapacidad son conscientes de lo difícil que es cumplir con dichas exigencias y requisitos.

\subsection{El malabarismo cotidiano: barreras estructurales para el desarrollo vital}

Un hecho significativo que se ha constatado en las entrevistas realizadas es que la conceptualización de las barreras cotidianas que perciben las mujeres con discapacidad está estrechamente ligada a la construcción de la identidad femenina y de las normas de género. Hay unas barreras específicas, sentidas por algunas de las mujeres con discapacidad y representantes del colectivo de las asociaciones de mujeres, que tienen que ver con el conflicto de no poder en ocasiones desempeñar de manera "autónoma" las tareas y las actividades, e incluso, los comportamientos supuestamente naturales atribuidos a las mujeres, como tender, llevar las bolsas o el carro de la compra...:

"Pa mí no existe la barrera, pero no dejo de reconocer que hay muchas limitaciones y hay muchísimas cosas para poder avanzar y estar igual que los demás. Aunque yo no sienta complejo ni ná pero no dejo de reconocer que está muy difícil la cosa, porque cuando no puedes alcanzar más de lo que puedes... po ya tú te sientes un poquito...[...] es el tender, que no puedo tender, dí por las circunstancias que no puedo tender, porque también tengo la 
mano cogida, la mano derecha. Entonces por mucho que quiera levantar la mano pa tender, porque pa tender hay que tender con dos manos y la mano no... no la levanto, y eso del día a día de tener que estar esperando a mi marío pa que venga y me tienda... juf! ¡me come los nervios!" (57 años, DF, 86\%).

"Yo voy por la calle y miro esa mujer que a lo mejor me lleva una ventaja de edad mu grande, mira como va andando y yo tan joven mira como estoy, y mira veo una mujer a lo mejor limpiando la puerta de la calle y digo mira de momento voy a estar yo haciendo eso, sí me veo un poco... discriminá, pero por mí misma, a mí no me está discriminando nadie, freno yo, freno yo por lo que soy capaz de hacer" (62 años, DF, 44\%).

"Yo... yo soy joven y yo veo a muchas mujeres que vienen del eco con sus dos bolsas de la compra y yo lo he hecho eso antes, pero ya dos o tres veces me ha dao un latigazo atrás por el peso y yo... que yo no tenga fuerza y esa mujer tan mayor va con esas dos bolsas, yo tengo que ir con el carro porque antes de que me de el latigazo y quedarme pará o dobla po voy con el carro a comprar o que me lleven con el coche" (43 años, DF, $70 \%$ ).

Las mujeres que más resaltan tener este tipo de barreras, sin embargo, no resaltaban demasiado sentir otros impedimentos como puedan ser las barreras en la participación social, de acceso a diferentes ámbitos como la educación, el empleo, las barreras simbólicas, las barreras arquitectónicas con respecto a cómo se configura el espacio normalizado, barreras mentales, barreras estructurales con respecto a la mayoría de los ámbitos de la sociedad que confieren valor y prestigio, y las que configuran ciudadanía. Al ser preguntada por estas cuestiones la presidenta de una de las asociaciones contactadas con respecto a las mujeres asociadas al colectivos identificaba lo siguiente:

"Con respecto a mí, las barreras de accesibilidad no, porque ya te digo no tengo barreras de accesibilidad realmente ¿no? Porque yo perfectamente puedo caminar ¿no? Con respecto a los demás usuarios en las barreras accesibles y con respecto a la mujer realmente las barreras más que veo son los accesos donde tiene que acceder la mujer con discapacidad para las revisiones ginecológicas. Es el mayor problema que estamos viendo, que te hablo como presidenta de la asociación ¿no? Porque ellas no pueden acceder a una revisión general de una revisión ginecológica normal y corriente como todo el mundo va ¿no? Ni incluso las revisiones de mamografía tampoco porque no están los mamógrafos adaptaos [...] Mayormente esa es la barrera mayor, fundamental que la encontramos nosotros de accesibilidad que no estén las consultas, que no tengan los horarios tampoco previsibles, porque claro para atender a una mujer con discapacidad como la tienen que subir al potro y eso y no está adaptao pues tienen que acudir a buscar a un enfermero y demás, tienen que tener más horas, los horarios de las consultan también están mucho más reducido porque son diez minutos a quince minutos y una mujer en esa hora no le da tiempo de atenderla ¿eh? La tiene que poner a primera hora o a última hora, eso no se está teniendo en cuenta en los centros hospitalarios ni en los centros de salud de momento" (39 años, DF, 33\%).

Para una mujer con discapacidad que utilice silla de ruedas, acceder a ciertos servicios sanitarios, como los ginecológicos que explica esta informante, supone una multitud de obstáculos añadidos. Las mujeres con discapacidad encuentran especiales dificultades en materia de accesibilidad, no sólo por la 
manera en la que los espacios son construidos a partir de un modelo estándar de cuerpo humano, sino también por lo usos distintos que se les da en función del género. Hay que tener presente que las barreras no solamente revelan un significado puramente material, sino que son representaciones de un ideario compartido de un modelo de individuo eficaz, competitivo, productivo, individualista e independiente, lo que se corresponde con el modelo androcéntrico moderno que toma al hombre blanco, de clase media, heterosexual y no discapacitado como medida de todas las cosas.

"Otra crítica así más en el tema de la accesibilidad por supuesto, accesibilidad pero de dentro de su hogar es lo que entendemos... las cocinas no están preparadas que es lo que más le interesa, porque por ejemplo en una casa si hay un hombre y una mujer pues las puertas más anchas y los baños porque todo el mundo tiene que ir, pero si es mujer la que tiene la discapacidad no tienen en cuenta la familia que la cocina la tienen que adaptar también para que ella pueda aprender a cocinar y desenvolverse. $Y$ eso es para hombre como para mujer pero no se tiene tanto en cuenta cuando es la mujer nada más no se hace hincapié de realmente de adaptar las cocinas, es algo más costoso, pero que vaya que las cocinas no están adaptadas, eso de la accesibilidad en el hogar es lo más reivindicativo" (39 años, DF, 33\%).

En este fragmento se vislumbra una conceptualización específica de barreras de accesibilidad atravesadas por el dispositivo de género, la accesibilidad del hogar, pero sobre todo de ciertas partes del hogar. Si bien la accesibilidad del hogar es una reivindicación más bien general, tanto para hombres con discapacidad como para mujeres con discapacidad, el hecho de hacer hincapié en la adaptación de ciertas partes del hogar, como la cocina, es un claro ejemplo de como el género atraviesa la vivencia de la discapacidad. La cocina se concibe pues, como un espacio delimitado simbólicamente por criterios de género, un espacio ocupado mayoritariamente por las mujeres por las actividades que en ella se suelen hacer.

Por otro lado, también se ha constatando otras perspectivas sobre las barreras cotidianas y estructurales. Por un lado, las barreras producidas por el contraste con un entorno estandarizado:

"En la vida cotidiana cualquier persona con discapacidad, en este caso grave como la mía, claro que tenemos barreras, tenemos barreras en el entorno, en los edificios, en el transporte. Cada uno en la medida en que puede lo va resolviendo, yo tengo, por ejemplo, mi coche particular adaptao por el que viajo a todas partes, luego digamos que la barrera del transporte más inmediata la tengo resuelta. Pero claro cuando llego a los sitios lógicamente me encuentro con las barreras propias que se encuentran todo el mundo. Todos tenemos barreras a la hora de participar en la sociedad y las famosas barreras mentales no digamos. Con eso nos encontramos todos" (No indica la edad, DF, 86\%).

Un aspecto de gran relevancia para estos colectivos de mujeres es el hecho de que su discapacidad suponga un hándicap para el desempeño laboral. En nuestra sociedad, el trabajo remunerado entraña una de las vías fundamentales de integración. Supone la fórmula para conseguir la independencia, la realización personal y el reconocimiento como miembros activos del grupo social. En este sentido, para un amplio número de mujeres las oportunidades de empleo se encuentran en el sector terciario; sector en el 
que el aspecto físico es, cada vez más, una cualidad necesaria y en el que es habitual que se exija "buena presencia" para la contratación. En nuestra sociedad, en relación al cuerpo y su culto, se le da gran importancia al cuerpo como imagen que transmite ciertos valores. Lo cánones de belleza (ser joven, guapa, delgada...) se relacionan también con los valores más prestigiados y valorados socialmente. Esto lo reconocen las mujeres con las que se realizó el primer contacto, así indica una de ellas:

"Yo sé que a mí me han descartado, porque yo sé que mi físico... pues no encaja" (35 años, DF, 45\%).

Esta discriminación comienza manifestándose en las dificultades que supone el acceso al mercado laboral, cuando se presentan a la entrevista de trabajo son sencillamente rechazadas para el puesto por el hecho de tener una discapacidad manifiesta, visible. De ello se deduce que quienes pretenden contratar se dejan llevar por los prejuicios y los valores interiorizados y que forman parte de nuestro habitus. Puede decirse, que huyen del estigma socializado como si éste fuera a convertirse - por simbiosis- en un estigma para la empresa o la entidad que contrata:

"Si vamos las dos y nos van a contratar, yo me imagino que por muchos estudios que yo tenga que te van a contratar a ti más porque creen que tú vas a responder más y mejor a ese puesto de trabajo que lo que a lo mejor puedo responder yo" (57 años, DF, 86\%).

Aunque ellas mismas señalan que son las mujeres con discapacidad física las que suelen manifestar en sus discursos una valoración más negativa de su imagen corporal, frente a las que tienen discapacidades sensoriales, por ejemplo, difíciles de identificar por la simple apariencia.

En esto que se viene exponiendo, es interesante destacar la existencia de factores considerados individuales y "personales", ya que se pueden concebir como una construcción mental propia de las mujeres, entre los que estarían la autopercepción negativa que las mujeres con discapacidad pueden tener de sí mismas (aunque claro está que esta "autopercepción" también es una percepción social), los factores familiares, como las diferentes trabas que obstaculizan el desarrollo integral de la mujer con discapacidad, y los fuertes factores sociales, como son los prejuicios sociales que plasman, por lo general, las empresas y el entorno comunitario. En este sentido, son reveladoras las palabras de las siguientes informante ante la identificación de impedimentos sociales para las mujeres con discapacidad, donde el estigma socializado las acompañan:

"Lo primero el trabajo. El trabajo para la mujer sin discapacidad ya tiene... entra el físico, pues para la persona con discapacidad más el físico, y el todo, entra todo. Si ya para una mujer normal es difícil, para una persona con discapacidad y para una mujer con discapacidad más, tanto intelectual, como física" (35 años, DF, 45\%).

"Lo primero que se debería trabajar en el caso de todas es la familia, que si la familia lo ve como una cosa normal entonces lo hace mucho más llevadero. En mi caso por ejemplo mi madre lo lleva muy mal, o sea yo con mi madre no puedo hablar de este tema, o sea mi madre se pone mala vamos parece que yo que sé que le va a dar... na más que le digo que tengo que ir a revisión, ya 
se pone a rezarle a to los santos que hay, se pone malísima. No sé claro eso... a mí porque es lo que te digo porque parece que yo que sé lo he asumido y lo llevo con normalidad y tampoco me afecta, pero si a lo mejor fuera de otra forma o tuviera otro carácter a lo mejor me afectaría y me sería mucho más complicao saber llevarlo con normalidad. Entonces yo creo que lo primero es que la gente que tú tengas a tu alrededor pues lo vea como un cosa normal que tampoco es nada... que... ¿sabes? Que te vaya a yo qué sé a impedir vivir vamos, entonces yo creo que eso es muy importante" (37 años, DS, 75\%).

Un entorno es un conjunto de formas concretas, de edificaciones, caminos, lugares que se configuran basados en actividades y formas de interacción de la población. Un ejemplo esclarecedor sobre los entornos y los contextos a los que se tienen que enfrentar estas mujeres es el episodio personal que cuenta esta mujer:

"Mi primera vez para buscar empleo, o sea me refiero a mi primera entrevista, era para trabajar en una oficina de un domicilio, o sea, domicilio donde está la oficina, de administrativo ¿vale? Para empezar yo llegué a la entrevista y para empezar yo me encontré con ocho escalones, ipara empezar!. Yo iba con mi hermana, y subimos las escaleras como pudimos ¡nadie nos echó una mano! Y pasaba gente pa arriba y pa abajo y nadie nos echó una mano. [...] llegué a la entrevista, llegó mi hora y a entrar pa dentro. Entré pa dentro y cuando a mí la mujer me vió, jautomáticamente fue verme y cambiarle dentro de su cabeza el chip de las preguntas que me iba a hacer! Y empieza -"bueno pues esto sería para trabajar de lunes a viernes, de ocho a tres, tendrías que venir, abrir la oficina, subir las persianas, poner la cafetera, ordenar el archivo"- Un archivo que llegaba de techo a suelo... y va hacer otra pregunta ella y le dije -"mire, pare usted ahí", digo -"pare usted ahí, sélleme la carta que ya hemos terminado, porque esto me parece una injuria, para empezar, porque ustedes ¿qué están pidiendo una administrativa o una chacha?, porque si está pidiendo una chacha entonces aquí estoy yo de sobra, porque mi puesto de trabajo es de administración" (33 años, DF, 80\%).

Aquí se plasma cómo los prejuicios sociales sobre las mujeres con discapacidad las construyen como incompetentes e incapaces, y son infravaloradas a la hora de insertarse en la estructura ocupacional, como es el caso de mi informante, diplomada universitaria y con un máster en finanzas. En la vida de las personas con discapacidad, es fundamental tratar de comprender los complejos sentimientos que suscitan los encuentros cotidianos con el mundo -estructurado desde la no discapacidad y la supuesta normalidad-. Discapacidad y género se tornan variables determinantes en la interacción social que estas mujeres establecen con el mundo "no-discapacitado". Algo espontáneo que surgió, con el grupo de mujeres con las que se tuvo el primer contacto, fueron las historias relativas a encuentros molestos, horribles, paternalistas, insensibles, inútiles $\mathrm{y}$, a veces, divertidos que tienen casi a diario con dependientes, personas que pasan por su lado por las aceras, ascensores, médicos, salas de espera, bares, cines... en definitiva, con cualquiera con quien se puedan cruzar. El hecho de que estos encuentros, junto con las preguntas, los comentarios y las miradas que los acompañan, sean casi siempre incómodos y molestos, nos obliga a no perder de vista en ningún momento lo difícil que es desarrollar las actividades ordinarias con unos cuerpos que son catalogados como no ordinarios. Aquí se destaca la violencia 
simbólica que se ejerce en muchas ocasiones con estas mujeres, las cuales reconocen identificar actitudes y sentimientos que les despiertan a la gente por sus miradas. Así lo relataba una mujer:

"Hay gente que te mira con curiosidad, como diciendo ¿qué será?, ¿qué tendrá? ¿sabes?, es que hay muchos tipos de miradas. Mira hoy me he ido a desayunar y una mujer todo el tiempo mirándome el cuerpo, los brazos, no sé, no sé, no sé si yo llevaba la misma camiseta que ella tiene o que le ha gustado y quiere una igual, porque yo he pasado por la terraza y esta mujer estaba desayunando y jse ha dado la vuelta! $Y$ ha hecho así [hace un gesto de sorprendida], joder y me ha faltado nada para decirle - ¡joye! ¿me doy la vuelta para que me veas mejor?"-. Otro día iba por una avenida hablando por teléfono y había una abuela sentada en un banco, y pasé por el lado de la abuela, y como me escuchó decir -"bueno venga que te espero abajo, venga hasta ahora"-, y dice: "“iescucha! Hasta ahora dice, mírala ella que eso va con su teléfono", y me dan ganas de decirle - ¡iseñora, que yo también tengo vida social!"- ¡Joder!” (33 años, DF, 80\%).

El mensaje cultural de ser cariñosos y cariñosas con los minusválidos ${ }^{18}$ es muy poderoso. Opera como un mecanismo que autoriza a ser paternalista con ellas, y a colocarse en una relación de poder muy potente. Esta postura de buena voluntad y de generosidad sirve a menudo para anular a las personas con discapacidad. Las mujeres informantes en este trabajo expresaron en numerosas ocasiones su rabia ante los sentimientos de compasión, la infantilización a la que eran sometidas y, por tanto, el mayor control que se ejercía sobre sus vidas:

"Es pena, compasión, te quieren ayudar, pero tú no quieres, pero por fuerza que sí... es que hay que decirlo muchas veces. [...] A mí me ha pasado en el autobús, de alguien querer sentarme por fuerza en el sitio, y yo que no, y seguía -"que se siente mujer, que sí"-, hasta que ya más seria le tuve que decir -"mire usted, que he dicho que no"- (33 años, DF, 80\%).

El hecho de tratar de comprender lo que sucede en estos encuentros, de analizar las reacciones es importante para comprender las relaciones de poder presentes en las relaciones entre las personas con discapacidad y las no discapacitadas. Resalto aquí especialmente el relato de la Presidenta de la Asociación Luna de Granada, con respecto a sus tipos de encuentros con personas "no discapacitadas":

"Una vez voy yo con mi hermana a un pub por la noche para tomarnos una copa, y había una mesa de billar y nos pusimos a jugar. [...] De repente se acerca un hombre y me coge por detrás y me dice -"esto se hace así"-, y le digo yo -"ya, ya lo sé, lo cojo como yo quiera"-, y dice el tío -"es que yo trabajo con personas como tú, te tendré que enseñar"- [lo dice con voz infantil imitando el modo en el que se lo dijeron] ¡Por favor!, y le digo yo - ¡vamos a ver caballero! ¿yo tengo puesto un cartel que ponga ¿si alguien sabe que me enseñe? ¿no, verdad?"-. Y el hombre insistía -"pero es que yo trabajo con personas como tú"- [vuelve a entonar de forma infantil], y le digo -"ijoder! Que me parece muy bien, si usted trabaja en lo que sea, y yo estoy aquí de ocio"(33 años, DF, 80\%).

\footnotetext{
${ }^{18}$ Lo vuelvo a poner en masculino intencionadamente.
} 
A lo largo de algunas entrevistas y conversaciones con las mujeres informantes, fueron numerosos los episodios y las experiencias que contaron a este respecto, y su interpretación de no sólo esa intromisión constante en sus vidas, sino también del control que ejercían sobre ellas. Este hecho se puede interpretar como una demanda que proviene del propia entorno, en el que ellas interaccionan y con el que se relacionan, de ejercer como "incapacitadas para" durante todo el día. El hecho de tener que pasar una parte significativa del día relacionándose con un mundo, físico y simbólico, diseñado históricamente para excluirlas y, todavía más agotador, tener que afrontar las concepciones previas o erróneas de otras personas sobre ellas mismas. Por otro lado, se puede inferir de la información obtenida que este tipo de situaciones se agudiza en el caso de mujeres con discapacidades visibles por la utilización de ayudas técnicas, como es el caso de la silla de ruedas. Las mujeres que hacían más hincapié en este tipo de encuentros eran aquellas mujeres que utilizan andadores y sillas de ruedas, sobre las cuales el significado inmediato de utilizar ese mecanismo, un andador o una silla de ruedas, les muestra a los demás su "diferencia". El entorno ordinario las estigmatiza a priori. Es, puede decirse, como si la persona que utiliza silla de ruedas estuviera obligada a ejercer de "incapaz" durante todo el día, porque en los encuentros cotidianos con el mundo, lo primero en lo que se fija la ciudadanía (hay que decir, no discapacitada) es en la silla de ruedas, por lo que su discapacidad queda hipervisibilizada. Las ideas acerca de lo que significa utilizar una silla de ruedas son tan abrumadoramente negativas y tan diferentes a la visión que algunas personas quieren tener de sí mismas que pueden ser muy destructivas. El hecho de que los demás las definan como ellas no se definen a sí mismas ha sido históricamente lo normal en la historia de las mujeres y, en este caso, de las mujeres con discapacidad. La gente puede sentir que es comprensiva con la desgracia de "personas de ese tipo", de "personas como tú", como indicaba la informante anteriormente destacada, pero ellas no lo ven así. Las sonrisas, las preguntas y los comentarios refuerzan la sensación de que, con independencia de la imagen que puedan tener de ellas mismas, la sociedad les impone una identidad negativa y gran parte de su vida social consiste en luchar contra ello. Los extraños no les permiten olvidar que la percepción de ellas está dominada por la diferencia como inferioridad:

"Es que te marca claro, te diferencia, es como yo comentaba es que te diferencia, es que tampoco no es lo mismo una discapacidad, por ejemplo, las que ellas tienen es visual entonces puede permitirse el lujo de decir bueno voy a una entrevista de trabajo y no digo nada pero es que tampoco se me nota, pero, por ejemplo, yo lo diga o no lo diga se me va a notar, nada más que te pongas a hablar conmigo ves que mi brazo no está bien, entonces ya me estás juzgando de una forma diferente a... si tú me vieras aparentemente bien, entonces eso es lo que a mí siempre me ha fastidiao" (44 años, DF, 33\%).

"En mi caso hay cosas que si estuvieran puestas de otra manera no me limitarían tanto. Por ejemplo, yo no puedo estirar el brazo del to, si hubiera... muchas veces ponen hasta cosas que tú dices es un llamador de no sé y yo no llego, o terrenos irregulares que me hacen ir andando mucho peor o un sitio que tienes que subir dos pisos y no sé qué y no hay otra forma... si todo estuviera mucho más accesible estaría más cómoda y se me notaría menos. Yo en mi casa no siento tanto mi discapacidad porque lo tengo todo a mano, 
puedo abrir, tengo no sé cuanto ¿eh? $\mathrm{Y}$ ahora de repente voy a un sitio a fuera y resulta que el grifo está super duro y no puedo abrirlo, que lo otro está... entonces me siento mucho más discapacitada, mucho más limitada que en otro contexto y eso depende del entorno no, a parte de las limitaciones que me ponga yo o que pueda tener, pero es lo que es la realidad el acceso a las cosas como estén, el mundo está hecho pa la gente que no tiene discapacidad, que no tienen dificultad, en el momento que tienes alguna cuesta más trabajo, si estuviera de otra forma adaptao pa to el mundo." (39 años, DF, 50\%).

Hay que indicar finalmente que todas las mujeres con discapacidad con las que se ha tenido contacto desarrollan su vida en el contexto urbano, por lo que es interesante apuntar -0 al menos dejar abierto para posibles desarrollos posteriores- la cuestión de que en las ciudades, sobre todo en las "grandes ciudades", se observan características comunes que afectan a la calidad de vida de las personas. La organización de las ciudades, que es el reflejo de los intereses económicos y políticos, han conllevado una pérdida de calidad de la vida de las personas. Tiene mucho sentido decir, que para las personas con diferentes tipos de discapacidades, la ciudad, en muchos aspectos es cada vez menos accesible y dificultosa, ya que pierden cuotas de autonomía, en lo que se refiere, por ejemplo, la cuestión de los desplazamientos y a la movilidad en un ritmo vertiginoso.

\subsection{Itinerario trazado para la discapacidad y el género}

Existen una serie de elecciones y decisiones del individuo, que están bajo determinaciones familiares -y del entorno más inmediato-, determinaciones estructurales y determinaciones de orden cultural y simbólico. Me refiero a los condicionamientos sociales que construyen ciertos caminos de posibilidad para las mujeres con discapacidad, y a la predisposición de ciertos itinerarios vitales condicionados, en este caso, por la construcción de género y la discapacidad (aunque también es totalmente imprescindible tener en cuenta la cuestión de la clase social). Los itinerarios vitales condicionados por el género y la discapacidad, se constituyen y someten a la estructura social:

"El nacer o el desembocar en una discapacidad lógicamente condiciona toda tu vida, no la determina, pero la condiciona. No puedes dejar de ser lo que eres, una persona con discapacidad, y eso va a condicionar tus procesos educativos, tu acceso a la formación, tu acceso a la participación en la sociedad en todos los aspectos lógicamente" (DF, 86\%).

Los itinerarios vitales de las mujeres tradicionalmente se han visto limitados con la confluencia de un conjunto de circunstancias diversas, como el género, la clase social, el estado civil, la edad, etc. La discapacidad convierte a las mujeres en objeto de cuidado constante, usurpándole de esta manera su dimensión activa, como sujeto protagonista de su vida. Esto se traduce en la limitación de ciertas posibilidades de existencia. Una sociedad dividida simbólica y empíricamente en dos géneros, significa que la estratificación económico-política y el reparto de sus roles responde a esa división por género; y toda sociedad construida sobre una profunda desigualdad genera mecanismos ideológicos que justifican y legitiman esa desigualdad. Por ello, el primer mecanismo ideológico eficaz, que apunta a la reproducción y reforzamiento de la desigualdad, es el estereotipo. Prácticamente, cualquier 
aspecto de la vida de las mujeres en esta sociedad tiende a estar subordinado a cumplir adecuadamente con el estereotipo femenino y función de género:

"A la mujer la echan a un lado como decir... pero bueno no te casas pero los padres egoístamente -"tú vas a estar con papá y mamá siempre de cuidadora"y sí que está haciendo las labores funcional de ama de casa, porque la que puede o está su casa adaptada o lo que sea está preparando la comida o lo que sea o como puede friega el suelo o limpian, porque hay mujeres que realmente lo hacen buscándose sus adaptaciones y sus mañas ¿no? Pero esos cuidados lo está haciendo como cuidadora, están... digamos esas dos perspectivas, que la rechazan de un lao en el que pueda acceder en buscar pareja y demás, en cambio el hombre no, el hombre tiene la discapacidad se procuran de formarlo, de darle los estudios mayor porque tiene que ser el cabeza de familia y lo preparan y lo forman. Y la niña no, a la niña no se le prepara el ajuar ni se le prepara educativamente ¿eh? Para que adquiera una formación, por lo menos para que sea más independiente, o ya dirá o no o tendrá la opción de casarse o no casarse igualmente, porque si está más puesta y más formá pues más probabilidades tiene de buscar una pareja o que le salga una pareja, igual que si la hubiéramos educao realmente igual al niño que a la niña desde pequeño ¿no? Esa diferencia sí que la vemos nosotros cuando se... y vaya que nos lo han manifestao en los estudios que hemos hecho de cómo han tratao a un hermano y a una hermana con la misma discapacidad y las opciones que daban, y hasta donde ha llegao su hermano y donde se ha quedao ella. Y querer ahora formarse, aprender a la informática, a los ordenadores, a hacer cursos, ha venío aquí... pero esas perspectivas sí que la hemos visto" (39 años, DF, 33\%).

Además del ámbito laboral al que se aludía anteriormente, hay que hacer referencia a los procesos educativos y formativos. La educación puede ser considerada - en el sentido que lo hace Bourdieu (1998)- un capital favorable para la promoción personal y social. Las desigualdades sociales encuentra su razón última en los niveles diferenciales de acumulación de los distintos capitales: educativo, cultural, relacional, simbólico y económico. La situación social de las mujeres tradicionalmente se ha caracterizado por la desigualdad tanto para acceder como para disponer de los distintos capitales sociales. Contamos con un sistema educativo escasamente adaptado a la discapacidad con aún graves deficiencias en accesibilidad física, escasas adaptaciones curriculares y, en general, escasez de recursos. Así se constata en las vivencias de segregación que cuentan estas mujeres en el contexto educativo, donde existe la tendencia a reforzar una idea de déficit individual en la discapacidad y, por lo tanto, de una intervención pedagógica que segrega y excluye imponiendo las fronteras y los límites entre los alumnos y las alumnas con necesidades educativas especiales y los normales:

"A mis padres le decían en el colegio que me metieran en un colegio especial porque rompía la dinámica de grupo" (35 años, DF, 45\%).

"A mi las monjas no me querían, y pensabas tú jjoder, que no soy un monstruo! Yo tenía siete años y tenía que ir a estudiar, y me estaban dando entonces quimioterapia, y tenía la cabeza y la cara pues un poco quemá, y decían las monjas que ni hablar, y fue mi madre a hablar con las monjas y las puso a parir, las puso a parir. [...] Mira al primer colegio que yo entré, en $1^{\circ}$ de EGB fue en San Rafael, y el director de San Rafael le decía a mi padre -"yo si fuera 
padre de esta niña no le dejaría aquí"-, allí había niños que no tenían un hogar y de to, con discapacidad intelectual... y estaban divididos por columnas. Bueno, luego me quitaron, estuve unos meses, y luego me cambiaron cuando abrieron el primer colegio en Granada que lo llamaban de integración social, entonces ahí me metieron" (33 años, DF, 80\%).

Unido a ello, contamos con un entorno generosamente sexista y estereotipado. A las mujeres con discapacidad se les designan tareas del ámbito privado, lo cual no está valorado. Desempeñan el rol que les han adjudicado como mujeres $\mathrm{y}$, en especial, como mujeres con discapacidad, asumiendo con bastante resignación valores y creencias patriarcales y estandarizadas. La percepción social que se tiene de las mujeres con discapacidad como personas con escaso potencial, necesitadas de ayudas y de prestaciones sociales, siendo no "competitivas" dentro del mercado de trabajo, afecta a las posibilidades que socialmente se ofrecen. Las personas con discapacidad, una vez que son catalogadas como tales, entran en un circuito diseñado institucionalmente, por lo que se marca un cierto itinerario de desarrollo vital. En este sentido, las mujeres con discapacidad tienen un itinerario trazado especialmente por su género y por su discapacidad. Por ejemplo, las mujeres con discapacidad tienen menos oportunidades para trabajar que las mujeres en general, debido a que sus oportunidades descienden cuando en un empleo no hay adaptaciones técnicas para que ellas puedan desarrollar el trabajo. Como indica una informante que utiliza silla de ruedas:

"Porque yo no puedo mostrar en una tienda nada de lo que hay más alto, ni para moverme... sí le digo -“¿usted ahí arriba lo ve? Pues cójalo usted misma porque yo no llego"-, eso no se puede hacer" (50 años, DF, 85\%).

En ocasiones ese itinerario diseñado que establece las posibilidades de vida es especialmente exacerbado por la construcción del género que hace el sistema patriarcal jerarquizando:

"Pues mira yo tengo también una queja. La mía es que yo toda mi vida he estao en mi casa al cuidao de mis hijos aguantando a mi marío hasta no poder más y yo veo muy injusto de que haya estao toda la vida aguantándole y que si cualquier día por $\mathrm{h}$ o por b... ahora se jubiló y sigo aguantándolo y ahora por $\mathrm{h}$ o por b, que tú te separes o cualquier cosa y que después de haber estao tooda la vida ahí, con lo malo y con lo bueno, que no tienes nada. [...] Después de que lo he aguantao toda mi vida, después que por cualquier cosa tú te tenga que separá y que tú no tengas nada, jno te pertenezca nada!" (48 años, DF, $41 \%)$.

Aquí se plasma cómo se construye un cierto itinerario vital para las mujeres, donde la disponibilidad, la dedicación y la distribución del tiempo es orientada al cuidado de los demás por interiorización del mandato de género, a través del cual se las predispone generalmente, ya sea por inercia social, por desconocimiento, o por otras motivaciones intencionadas, a una socialización sexista desde niñas. 


\subsection{La violencia institucionalizada y la discriminación basada en la discapacidad y el género}

Existen determinadas formas de violencia que solamente pueden ejercerse sobre las mujeres. La violencia de género, en todas sus vertientes de sometimiento que implica una denigración de lo considerado "femenino" (en su nivel simbólico, cultural, político, económico y corporal), deriva de la desigualdad de partida entre hombres y mujeres. Este tipo de violencias cuenta con el respaldo de una estructura social anclada en las múltiples formas de dominación que existen. Es por este motivo por el que se convierte en violencia institucionalizada, en tanto que cuenta con una legitimación y respaldo anclado en la organización social para perpetuarse y reproducirse en los diferentes ámbitos sociales. Esta violencia aumenta en el caso de las mujeres con discapacidad, donde se puede generar una especial opresión. Es por ello, por lo que expongo relatos esclarecedores en los que las mujeres identifican la discriminación (un tipo de violencia) que han vivido en muchos aspectos de sus vidas:

"Yo hice un master financiero para trabajar en Caja Granada. Yo estuve dos meses de prácticas en Caja Granada y al cabo de los dos meses me largaron ¿por qué? ¿yo no soy válida para estar en un mostrador en caja? ¿yo no soy válida para estar en intervención dando préstamos? Que yo sepa estoy preparada y formada para ello, y otros compañeros que estudiaron conmigo entraron, y yo sin embargo fue terminar mis dos meses de prácticas iy a la puta calle! Muy claramente. $Y$ hablé con la coordinadora y me dijo que es que yo no cumplo el perfil, pero perdona ¿qué perfil hay que cumplir?, porque que yo sepa todos están sentados en la oficina, y tengo mi master y mi formación" (33 años, DF, 80\%).

"Yo una vez quise hacer unas oposiciones a banco y entré en una academia y me dice un chico -"mire yo le voy a ser muy sincero porque prefiero ganar una amiga y perder una clienta. Mira tú te matricularás, harás el curso, aprobarás porque te estoy viendo que estás totalmente capacitada y que tienes un nivel, pero en la entrevista personal te echarán por incompetencia, y lo sé porque me ha pasado muchas veces, y no lo pienso hacer ni una vez más"-, y le dije pues muchísimas gracias y hasta luego" (50 años, DF, 85\%).

\section{A MODO DE CONCLUSIÓN}

En el centro de la pretensión de constituir una perspectiva nueva se encuentra la idea de que la discapacidad está producida: lo cual es distinto de la idea de que se trata sencillamente de una anormalidad médica o fisiológica; distinto de la idea de una desviación construida socialmente (Oliver, 1998: 39-40).

La discapacidad, como fenómeno social, ilustra una imposición identitaria fundada en unas determinaciones jerárquicas socialmente definidas, aunque evidentemente las mujeres como sujetos desarrollan estrategias de resistencia y de empoderamiento. Las personas con diferentes discapacidades "se dan cuenta" de su diferencia, no la construyen. Por lo que esa diferencia es definida por el mecanismo de heteronomia (Ferreira y Rodríguez Caamaño, 2006), es 
decir, la diferencia es definida por el otro y, a su vez, la identidad que de ella surge no es una según la cual la discapacidad constituya un hecho propio diferenciador, sino la ausencia de rasgos identitarios respecto al otro.

En este mismo sentido, la construcción de "la mujer", como ya indicaba Simone de Beauvoir (1949), y la discapacidad son una heterodesignación. Esto tiene más sentido -aún si cabe- en el caso de las mujeres con discapacidad. La discapacidad es un claro ejemplo de heterodesignación. A las mujeres con discapacidad siempre les han predicado lo que son y lo que deben ser y hacer, ya que en un sistema patriarcal y normalista como en el que nos situamos, existe una forma de estar y ser hegemónica y normativa, que se convierte en patrón a seguir para señalar y modelar todas aquellas formas que se salgan de los parámetros biológicos, conductuales, mentales, físicos, actitudinales, políticos y sociales de estar y de ser.

Los sujetos convertidos en discapacitados/as son lo "otro", diferentes de lo establecido dentro de lo normal. Nos podríamos hacer preguntas que ayudan a relativizar el concepto de discapacidad: ¿es la discapacidad un concepto universalmente aplicable en todas las sociedades?. Muchas de las deficiencias a nivel mundial son el resultado de la extrema pobreza, la malnutrición, la falta de agua potable por un saneamiento deficiente y las condiciones de trabajo (OMS, 2001). Todo ello, me lleva a la conclusión de que muchas de las deficiencias catalogables como discapacidad son de modo muy claro la consecuencia principalmente de factores sociales y políticos, y no un inevitable hecho natural. Esta visión conlleva la interconexión de individuos, grupos y comunidades en redes económicas, políticas y culturales, y la cual, a su vez, supone una aceleración en la imposición de un orden capitalista mundial. Como consecuencia, "las tendencias discapacitantes asociadas con el desarrollo económico y cultural de influencia occidental, es decir, industrialismo, urbanización, autosuficiencia y la normalidad del "cuerpo capaz" son replicadas a lo ancho y largo de todo el planeta" (Barnes, 2010: 13-16).

Como revela la información analizada a partir de las entrevistas, se puede decir que la discapacidad es consecuencia de unas estructuras sociales que se han erigido en función de unos requerimientos que no han tomado en consideración las específicas necesidades de muchas personas y, en virtud de ello, las han convertido en un colectivo sometido a la opresión. No hay individuos discapacitados, hay un orden social discapacitante que convierte a los sujetos con ciertos déficits en discapacitados en su entorno. La discapacidad es también históricamente cambiante. La discapacidad y el género, como la etnia, la clase social... forman parte de una estructura de dominio, como bien apunta Barton (1998: 26). Esto supone el rechazo de una visión sumativa de la opresión a favor de una idea de entrelazado y de dialéctica. El apelativo de "discapacitada" se puede tornar subversivo para convertirlo en una insignia de identidad y cierta desobediencia ante la hostilidad del entorno.

En la noción misma de discapacidad, en las formas en que ella se concibe están contenidas consecuencias específicas para las mujeres, como se refleja en el informe de investigación. Asignarle el carácter de algo dado, natural a la discapacidad supone una idea en la cual se compara un cuerpo "normal", completo, sin fallas que se constituye como el ideal, como el que todos queremos tener, con otro cuerpo que se presenta fuera de esas condiciones (Almeida et al, 2010: 38), figura que históricamente ha sido representada por el 
cuerpo de las mujeres. En esta perspectiva, la discapacidad se piensa como una producción social, inscrita en los modos de producción y reproducción de una sociedad. Discapacitada/o refiere a alguien que es producido como tal en el marco de un tipo de relación de poder.

Para las mujeres, como queda reflejado, la discapacidad condiciona la forma que tienen de relacionarse con el mundo, configurándose como un factor estigmatizante en la construcción de su identidad, al igual que otros elementos de sus vidas como el género. Así pues, la discapacidad puede ser considerada, sin lugar a dudas, una variable que contribuye a la construcción de la identidad y la personalidad de las mujeres que presentan algún tipo de déficit. Como señala Shakespeare (1998: 205-209), los estereotipos sexuales refuerzan los prejuicios sobre la discapacidad, ya que en los casos de mujeres y hombres con discapacidad, la dependencia, la vulnerabilidad y la debilidad son las asociaciones en la cultura patriarcal. Por consiguiente, las mujeres discapacitadas se representan de una manera especialmente negativa y pasiva.

Se puede admitir que la múltiple opresión de las mujeres con discapacidad se manifiesta en realidades tan objetivas y evidentes como el empleo, salarios inferiores, menor acceso a los servicios de salud, mayores carencias educativas, mayor riesgo de sufrir violencia de género, ser consideradas como asexuadas; en definitiva, se caracteriza por una marcada desigualdad social que coloca a muchas mujeres con discapacidad en una determinada posición marginal de la estructura social.

Hay que decir que las mujeres informantes que fueron entrevistadas se caracterizan por situarse en una determinada posición dentro de la estructura social, en términos de clase. Una clase social que ya no se define exclusivamente en términos del trabajo (como empleo) como única fuente de identidad de clase y por la estructura ocupacional, sino que trasciende esta visión al incluir las múltiples diferenciaciones sociales y desigualdades que se producen en las sociedades capitalistas postindustriales actuales, y que intervienen en la posición que se ocupa en la jerarquía social. Por tanto, la discapacidad y el género se presentan como elementos claves para la composición de clase social, puesto que son elementos que también determinan la estratificación social. Encuadrar la realidad social de las mujeres con discapacidad supone comprender las implicaciones que conlleva esta lógica práctica para la existencia cotidiana que está sujeta a la singularidad propia de la condición de discapacidad y de género. El habitus de la mujer discapacitada se va constituyendo como un reflejo en negativo de la integridad efectiva en la vida práctica de la ciudadanía (Ferreira y Rodríguez Caamaño, 2006). Se va construyendo la experiencia cotidiana, aprendiendo que la función práctica consiste en evitar obstáculos, la práctica cotidiana se puede convertir en un auténtico ejercicio de "malabarismo".

Como mujeres, la politización de la discapacidad tiene sus raíces en la afirmación de que "lo personal es político", que las experiencias personales respecto a la denegación de oportunidades no hay que explicarlas solo por medio de las limitaciones corporales, sino por las barreras sociales, ambientales y de actitud que forman parte de nuestra vida cotidiana. Por ello, se puede decir que históricamente las mujeres han sido consideradas y producidas como las eternas discapacitadas. Existe una acumulación de 
barreras y discriminaciones, tienen que trabajar más que el varón, con menor reconocimiento social, con menosprecio del trabajo doméstico. Así, se puede llegar a decir que desde el punto de vista de cómo se ha construido y representado socialmente la "identidad femenina", la condición femenina históricamente a partido con un hándicap.

\section{REFERENCIAS BIBLIOGRÁFICAS}

(2010) ALMEIDA et al., "Nuevas retóricas para viejas prácticas. Repensando la idea de diversidad y su uso en la comprensión y abordaje de la discapacidad". En Política y Sociedad, vol. 47. Núm. 1:27- 44.

(2004) ARNAU RIPOLLÉS, Soledad, "Violencia de género contra la(s) Mujer(es) con discapacidad(es)". Ponencia presentada para el Seminario Violencia de género y discapacidades, organizado por Eraberri, Vitoria-Gasteiz, 7 y 8 mayo.

(2010) BARNES, Colin, "Discapacidad, política y pobreza en el contexto del Mundo Mayoritario". En Política y Sociedad, vol. 47. Núm. 1: 11-25.

(1998) BARTON, Len, "Sociología y discapacidad: algunos temas nuevos". En Discapacidad y Sociedad. Madrid. Morata, pp. 19-33.

(2008 [1967]) BERGER, Peter y LUCKMANN, Thoman, La construcción social de la realidad. Amorrortu, Buenos Aires.

(2007 [1998]) BOURDIEU, Pierre, La dominación masculina, Anagrama, Barcelona.

(1997) BOURDIEU, Pierre, Razones prácticas: sobre la teoría de la acción, Anagrama, Barcelona.

(1992 [2005]) BOURDIEU, Pierre y WACQUANT, Loïc, Una invitación a la sociología reflexiva. Siglo Veintiuno Editores, Buenos Aires.

(2012) CABALLERO, Isabel, "Salud". En La transversalidad de género en las políticas públicas de discapacidad, Volumen I, Colección Cermi.es, № 54, febrero 2012. Ediciones Cinca, S. A, pp. 311-337. Madrid.

(2011 [1949]) DE BEAUVOIR, Simone, El Segundo Sexo, Cátedra. Madrid.

(2010) FERREIRA, Miguel A.V, "De la minus-valía a la diversidad funcional: un nuevo marco teórico-metodológico", en Política y Sociedad, Vol. 47 , №1, pp 45-65.

(2006) FERREIRA, Miguel A.V. y RODRíGUEZ CAAMAÑO, Manuel. J. "Sociología de la discapacidad: una propuesta teórica crítica", en Nómadas, Revista crítica de ciencias sociales y jurídicas, 13. 
(2001 [1963]) GOFFMAN, Erving, Estigma. La identidad deteriorada. Amorrotu, Buenos Aires.

(1998) OLIVER, Mike, "¿Una sociología de la discapacidad o una sociología discapacitada?", En Barton, Len (Comp.), Discapacidad y Sociedad, pp. 34-56. Ediciones Morata, Madrid.

(2009) OMS, Las mujeres y la salud. Los datos de hoy, la agenda de mañana, http://whqlibdoc.who.int/hq/2009/WHO_IER_MHI_STM.09.1_spa.pdf

(2001) OMS, Clasificación Internacional del Funcionamiento, de la Discapacidad $y$ de la Salud (CIF), http://www.imsersomayores.csic.es/documentos/documentos/oms-clasificacion02.pdf

Real Decreto 1856/2009, de 4 de diciembre, de procedimiento para el reconocimiento, declaración y calificación del grado de discapacidad.

(2009) ROBLES SANJUAN, Victoria, "La extraña relación entre la "INCAPACIDAD DE" y la "SOBRECAPACIDAD PARA" en la literatura escolar para niñas y mujeres (siglos XIX y XX)". En Mañas, Carmen (Coord.), Mujeres y diversidad funcional (discapacidad): construyendo un nuevo discurso, pp. 119132. Colección FEMINISMO/S, Revista del Centro de Estudios sobre la Mujer de la Universidad de Alicante, Número 13.

(2009) ROSATO, Ana et al, "El papel de la ideología de la normalidad en la producción de discapacidad". En Ciencia, Docencia y Tecnología № 39, Año XX, noviembre, pp 87-105.

(2000) SENNET, Richard, La corrosión del carácter. Las consecuencias personales del trabajo en el nuevo capitalismo, Anagrama, Barcelona.

(1998) SHAKESPEARE, Tom, "Poder y prejuicio: los temas de género, sexualidad y discapacidad”, pp. 205-229. En Barton, Len, Discapacidad y Sociedad, Morata, Madrid.

(2009) SHUM, Grace y CONDE, Ángeles, "Género y Discapacidad como moduladores de la identidad". En Mañas, Carmen (Coord.), Mujeres y diversidad funcional (discapacidad): construyendo un nuevo discurso, pp. 119132. Colección FEMINISMO/S, Revista del Centro de Estudios sobre la Mujer de la Universidad de Alicante, Número 13.

(2004) TORRES DÁVILA, Mํㅗ Soledad, Género y discapacidad: más allá del sentido de la maternidad diferente. Maestría en Estudios de Género, FLACSO sede Ecuador. 171 Págs. 